\title{
Capsule Commentary on Schiavoni et al., How Primary Care Physicians Integrate Price Information into Clinical Decision Making
}

\author{
Maria G Frank, MD FACP, FHM \\ Denver Health Hospital Authority, Denver, CO, USA.
}

J Gen Intern Med 32(1):92

DOI: $10.1007 / \mathrm{s} 11606-016-3849-1$

(c) Society of General Internal Medicine 2016

I $\mathrm{n}$ this month's edition, Schiavoni ${ }^{1}$ and colleagues describe their cross-sectional qualitative study in which they conducted semi-structured interviews of 46 primary care physicians (PCPs) from an accountable care organization (Atrius Health) to better understand PCPs' experience with disclosure of price information on tests and procedures. The key findings of this study were that PCPs were more interested in having patient-specific out-of-pocket price information than the price paid by insurers, which would not necessarily have an impact on patients' day-to-day finances. Having cost information enabled providers to involve patients in treatment discussions and to make informed choices regarding reasonably priced medical care. PCPs reported that they were unlikely to change their ordering patterns regardless of displayed cost information, yet financial information was perceived as helpful when trying to avoid patient-driven unnecessary testing. Also, most PCPs agreed that price transparency in healthcare is crucial and that it requires the engagement not only of patients and practices, but also of society and healthcare payers (health plans).

The study ${ }^{1}$ results contrast with those previously published. Goetz et al. ${ }^{2}$ identified 17 articles analyzing the effect of displayed charges for both laboratory and radiology orders as well as medication choice; they concluded that charge information changed ordering and prescribing practices. These results are consistent with those found by Horn et. al. ${ }^{3}$ Sinaiko el al. ${ }^{4}$ also describe the potential benefit that price transparency has on health cost savings; however, they focus on patient- led interventions rather than changes in physician prescribing practices. The authors hypothesize that incorporation of cost information into daily practice may influence providers' perceptions of the degree to which this data influences their ordering and prescribing patterns. This complex dynamic may contribute to the differences found between Schiavoni's results and those previously published.

In an era of patient-centeredness, high-value care and the Choosing Wisely ${ }^{\circledR}$ campaign, healthcare cost information seems to be important to providers and patients alike; however, further research is needed to help determine how best to incorporate cost transparency into everyday practice.

Corresponding Author: Maria G Frank, MD FACP, FHM; Denver Health Hospital Authority, Denver, CO, USA (e-mail: Maria.frank@dha.org).

\section{Compliance with Ethical Standards:}

Conflict of Interest: The author has no conflicts of interest with this article.

\section{REFERENCES}

1. Schiavoni K, Lehmann LS, Guan W, Rosenthal M, Sequist TD, Chien AT. How primary care physicians integrate price information into clinical decision making. J Gen Intern Med. 2016. doi:10.1007/s11606-016-3805-0.

2. Goetz C, Rotman SR, Hartoularos G, Bishop TF. The effect of charge display on cost of care and physician practice behaviors: a systematic review. J Gen Intern Med. 2015;30(6):835-842. doi:10.1007/s11606-015-3226-5.

3. Horn DM, Koplan KE, Senese MD, Orav EJ, Sequist TD. The impact of cost displays on primary care physician laboratory test ordering. J Gen Intern Med. 2013. doi:10.1007/s11606-013-2672-1.

4. Sinaiko AD, Chien AT, Rosenthal MB. The role of states in improving price transparency in health care. JAMA Intern Med. 2015. doi:10.1001/ jamainternmed.2015.0628.

Published online November 18, 2016 